\title{
Preparation and characterization of insulin-loaded injectable hydrogels as potential adjunctive periodontal treatment
}

\author{
Ali Raeef Abboud ${ }^{1, A-D}$, Ali Mohammad Ali ${ }^{2, A, C, E, F}$, Tihama Youssef ${ }^{1, A, E, F}$ \\ ${ }^{1}$ Department of Periodontics, Faculty of Dentistry, Tishreen University, Lattakia, Syria \\ ${ }^{2}$ Department of Food Technology, Faculty of Technical Engineering, University of Tartous, Syria \\ A - research concept and design; $B$ - collection and/or assembly of data; $C$ - data analysis and interpretation; \\ $\mathrm{D}$ - writing the article; $\mathrm{E}$ - critical revision of the article; $\mathrm{F}$ - final approval of the article
}

\section{Address for correspondence \\ Ali Raeef Abboud}

E-mail:ali.abboud90@gmail.com

Funding sources

None declared

Conflict of interest

None declared

Acknowledgements

We would like to thank the Faculty of Technical Engineering, University of Tartous, Syria.

Received on March 2, 2020

Reviewed on July 18,2020

Accepted on July 23, 2020

Published online on December 31, 2020

Cite as

Abboud AR, Ali AM, Youssef T. Preparation and

characterization of insulin-loaded injectable hydrogels as potential adjunctive periodontal treatment. Dent Med Probl. 2020;57(4):377-384. doi:10.17219/dmp/125658

DOI

$10.17219 / \mathrm{dmp} / 125658$

Copyright

○) 2020 by Wroclaw Medical University

This is an article distributed under the terms of the

Creative Commons Attribution 3.0 Unported License (CC BY 3.0)

(https://creativecommons.org/licenses/by/3.0/).

\begin{abstract}
Background. The application of local drugs as adjunctive periodontal treatment is a topic of rapidly increasing interest. Consequently, new discoveries are arising, a noteworthy portion of which employ hydrogels as delivery systems due to their high biocompatibility with and similarity to human tissues. In the search for new therapeutic agents capable of aiding periodontal treatment, authors became interested in a unique concept investigated by very few in vitro or in vivo studies concerning the local application of insulin. These studies concluded that insulin promotes the recovery and regeneration of damaged soft and bone tissues.

Objectives. The aim of the study was an endeavor to design a linear hydrogel that is injectable into periodontal pockets, and is able to carry a small insulin load through physical bonds and provide sustained release.

Material and methods. The chitosan hydrogel as well as blends of polyvinyl pyrrolidone (PVP), polyvinyl alcohol (PVA) and polyethylene glycol (PEG) were prepared and characterized in terms of the hydrogel texture and injectability. Afterward, to study the insulin release kinetics, a specific amount of each formulation was loaded with insulin, and then incubated in phosphate-buffered saline (PBS). Specimens of the incubated samples were withdrawn daily to measure insulin concentrations by means of the ultraviolet (UV)-absorbance method; ultimately the cumulative release was calculated.

Results. Out of the 5 formulations, 4 had homogenous one-phasic texture and their insulin release profiles in vitro ranged from a few hours to about 2 weeks. The blend of $26.5 \mathrm{wt} \%$ PVP, $6.6 \mathrm{wt} \%$ PVA, $0.03 \mathrm{wt} \%$ calcium chloride dihydrate $\left(\mathrm{CaCl}_{2} .2 \mathrm{H}_{2} \mathrm{O}\right)$, and $66.8 \mathrm{w}$ t\% water, loaded with $2 \mathrm{IU} / \mathrm{g}$ of insulin, had favorable regular sustained release, approaching 13 days.

Conclusions. The composition of the hydrogel, the component ratio and the amount of loaded insulin were found to affect the release profile. A linear hydrogel of copolymerized PVP, $\mathrm{PVA}$ and $\mathrm{CaCl}_{2} 2 \mathrm{H}_{2} \mathrm{O}$ can serve as a local vehicle for the sustained delivery of insulin inside periodontal pockets.
\end{abstract}

Key words: insulin, hydrogel, cumulative release, periodontal pockets, UV-absorbance 


\section{Introduction}

Handling gingival and periodontal disease is not a simple mission. Plaque-induced gingivitis can be resolved by biofilm removal and scaling procedures. Still, to preserve healthy gingiva, the maintenance of self-performed oral hygiene is indispensable. Non-surgical periodontal therapy (NSPT), a cornerstone in managing periodontitis, precedes any additional therapy. To accomplish it, practitioners use scalers and pocket/root instrumentation in order to approximate the ultimate goal of the therapy, which is to remove microbial deposits and calculus from the supra- and infragingival areas. ${ }^{1}$ Besides that, a variety of treatment strategies can modulate the patient's response to the management of periodontitis. This involves the local application of chemotherapeutic agents as an adjunct to NSPT, increasing its ability to ensure satisfactory outcomes. In the medical literature, most local drugs that are applied for treating periodontitis can be divided into antibiotics, antiseptics, anti-inflammatory drugs, growth factors, interleukins, and medicinal herbal products. ${ }^{2,3}$

An ideal local drug delivery system (LDDS) should provide a gradual release of the active drug for a sensible period, and be biocompatible, bioadhesive and noncytotoxic. ${ }^{4-6}$ In patients with periodontitis, periodontal pockets themselves are available as natural reservoirs for LDDSs. At first, subgingival irrigating systems can supply therapeutic agents to the diseased area at effective concentrations, but conspicuous limitations arise from the continuous flow of the gingival crevicular fluid (GCF), which is replaced approx. 40 times per hour, leading to the rapid clearance of subgingivally placed drugs. Any added clinical advantage subgingival irrigation may have over NSPT is probably limited to drugs that can bind to the surface of the root and/or lining of the periodontal pocket, such as tetracyclines or chlorhexidine. ${ }^{1}$

Recognizing that the potency of a locally applied medicine hinges on its relatively long-lasting availability at concentrations over the effective minimum, several forms of LDDSs have emerged. They include fibers, strips, films, gels, microparticles, and nanoparticles, all aiming to offer easy application, steadiness and uniform distribution inside periodontal pockets as well as controlled or sustained release. Local delivery systems for various drugs have been designed in in vitro and/or in vivo studies, and their drug release profiles, architecture and the clinical outcomes of their application have been described. ${ }^{7-9}$ Quite a number of efficiency-proven LDDSs are commercially available, and some are approved by the U.S. Food and Drug Administration (FDA). Actisite ${ }^{\circledR}$ is a non-resorbable fiber made of ethylene/vinyl acetate copolymer, measuring $23 \mathrm{~cm}$ in length and $0.5 \mathrm{~mm}$ in diameter, with evenly dispersed tetracycline hydrochloride $(\mathrm{HCl}) .^{7}$ This product is now discontinued, probably because of difficulties in handling it during placement and its nonbiodegradable nature. Recently, a product called Periodontal Plus $\mathrm{AB}^{\mathrm{TM}}$ has been presented, containing $2 \mathrm{mg}$ of evenly impregnated tetracycline $\mathrm{HCl}$ in $25 \mathrm{mg}$ of pure fibrillar collagen. Periodontal Plus $\mathrm{AB}$ releases tetracycline gradually and dissolves in 8-12 days. ${ }^{8}$ PerioChip ${ }^{\circledR}$ is an FDA-approved rectangular chip $(5 \mathrm{~mm} \times 4 \mathrm{~mm} \times 0.3 \mathrm{~mm})$ containing $2.5 \mathrm{mg}$ of chlorhexidine gluconate, embedded in the matrix of a biodegradable polymer - gelatin. ${ }^{9}$

Gels combine the ease of fabrication and application, enough to have made them the most popular form of local drug carriers. For example, a xanthan gum-based gel containing $1.5 \%$ chlorhexidine, called Chlosite ${ }^{\circledR}$, is available in place of PerioChip. Ligosan ${ }^{\circledR}$ Slow Release is a hydrogel matrix loaded with $14 \%$ doxycycline $(w / w)$. The matrix is composed of copolymerized polyglycolic acid and poly(poly(oxyethylene)-co-DL-lactic acid/glycolic acid). ${ }^{10}$ Delivery systems can be mixable before use, such as Atridox $^{\circledR}$, an FDA-approved LDDS for doxycycline hyclate into the subgingival sites. One syringe contains the Atrigel ${ }^{\circledR}$ delivery system, which has $36.7 \%$ poly(DL-lactide) as a solute and 63.3\% N-methyl-2-pyrrolidone as a solvent; another syringe holds $50 \mathrm{mg}$ of doxycycline hyclate. Mixing the components from the 2 syringes results in a viscous liquid with $10 \%$ doxycycline hycalte, which solidifies quickly and begins controlled release. Periofilm $\mathrm{T}^{\circledR}$ is a local delivery system that consists of an antibiotic powder (100 mg of sodium piperacillin, $12.5 \mathrm{mg}$ of sodium tazobactam) and a liquid (aminoalkyl methacrylate copolymer, ammonium methacrylate copolymer, $95 \%$ ethanol, and purified water). ${ }^{11}$ The components should be mixed immediately before application. Gelatinous formulations for the delivery of minocycline $\mathrm{HCl}$ are also commercially available, e.g., Dentomycin ${ }^{\circledR}$ in the European Union and Periocline ${ }^{\circledR}$ in Japan. ${ }^{3}$ Elyzol $^{\circledR}$ Dental Gel is a popular delivery system for metronidazole. It is composed of a semi-solid suspension of $25 \%$ metronidazole benzoate in the mixture of glyceryl monooleate and sesame oil; its viscosity should increase after placement. ${ }^{1}$ One of the microparticle-based subgingival delivery systems is Arestin $^{\mathrm{TM}}$ - FDA-approved microspheres synthesized from poly(lactic-co-glycolic acid) (PLGA) for releasing minocycline $\mathrm{HCl}$ sustainably inside periodontal pockets. ${ }^{12}$

Human insulin - the hormone of $\beta$ cells in the Langerhans islets of the pancreas - consists of 2 peptide chains called $A$ and $B$, linked via 2 intermolecular disulfide bridges. Insulin receptors (IRs) are transmembrane receptors with tyrosine kinase activity, existing on almost every cell. The activation of the IR substrate by insulin binding initiates a signaling cascade regulating the transport and usage of glucose in the liver and other cells. Thereby, insulin stimulates sugar storage and amino acid synthesis in the liver. In addition, it controls ATP production and fatty acid synthesis in muscles and adipose tissue. ${ }^{13}$

Many scientists have long regarded insulin-like growth factors (IGFs) as major regulators of cell proliferation, survival and organism growth, while insulin has been considered a dominant controller of energy storage and usage. But some researchers deem this concept simplistic due to evidence that the roles of IGFs and insulin overlap 
in several physiologic processes. ${ }^{14}$ In vitro studies have proven that insulin increases the proliferation and differentiation of wild-type osteoblasts by suppressing the Runx2 inhibitor Twist $2,^{15}$ and simultaneously increases the markers of bone resorption. ${ }^{15,16}$

The healing of the supporting alveolar bone, following surgical or non-surgical periodontal therapy, passes through 3 sequential phases - inflammation, repair and remodeling. During the inflammation phase, some events can be distinguished as preparation for repair. Cells from myeloid and mesenchymal cell lineages are attracted to the area, and begin to differentiate into osteoblasts and chondroblasts. ${ }^{1}$ Evidence of IGF-1 having an anabolic role in bone is abundant in the literature, whereas evidence that its homolog - insulin - also plays such a role is still accumulating. Pre-osteoblasts and osteoblasts possess different isoforms of IR, where IR-A is expressed in pre-osteoblasts and IR-B is expressed in osteoblasts. This specificity supports the idea that insulin is a critical factor in the differentiation of osteoblasts from marrow stromal cells. ${ }^{17}$ Interleukin 6 (IL-6) contributes to the mediation of chronic low-grade inflammation (including chronic periodontitis). It has been found in vitro to induce cellular insulin resistance by inhibiting IR signal transduction, ${ }^{18}$ and increasing the expression and activity of insulin-degrading enzymes. ${ }^{19}$ Thrailkill et al. bred mice with the osteoprogenitor-selective ablation of IRs. ${ }^{20}$ The prenatal elimination of IRs resulted in osteoblasts lacking $80 \%$ IRs, which in turn led to a decrease in the structural strength of the femur bone postnatally as compared with mice which had normal IRs. It therefore makes sense to investigate how effective the local delivery of insulin is in compensating for the cellular insulin resistance caused by periodontitis, which could enhance the quality of bone repair with a cost-effective method.

A few in vivo and clinical trials have studied the local application of insulin to determine its safety and influence on wound healing, ${ }^{21-24}$ recovery from decubitus ulcers, ${ }^{25}$ bone healing and regeneration, ${ }^{26,27}$ and the osseointegration of titanium implants. ${ }^{28}$ In these studies, researchers demonstrated that the local application of insulin correlated with statistically significant acceleration in the variables studied. At the same time, the studies noted no adverse effects or significant differences in blood glucose levels before and after application. ${ }^{16,21,23-25,29}$ Paglia et al. reported greater acceleration in the early phase of bone healing in a non-diabetic, fractured Wistar rat model after local injections of insulin. ${ }^{27}$ Wang et al. cultured bone marrow stem cells within nano-hydroxyapatite/collagen/ PLGA composite scaffolds, either loaded or not loaded with insulin, and observed higher rates of osteogenesis and mineralization in the insulin-loaded ones, especially at the primary bone formation stage. ${ }^{26}$

The promising results of the local application of insulin mean it is a reasonable idea for us to design a delivery vehicle for insulin, with a view to investigating the effectiveness of insulin in promoting periodontal regeneration after NSPT for periodontitis. Ideally, the vehicle should be capable of providing sustained release during the primary healing period after periodontal treatment $\left(1-3\right.$ weeks $\left.{ }^{30}\right)$.

Particular interest in hydrogels still prevails, as biomaterials benefit from high water retention, effective mass transfer, similarity to natural tissues, and the ability to form different shapes. ${ }^{31}$ We chose 3 synthetic medical polymers - polyvinyl pyrrolidone (PVP), polyvinyl alcohol (PVA) and polyethylene glycol (PEG) - and a natural polymer (chitosan) on the basis of the long-term historical usage of these polymers in the pharmaceutical industry, wound dressing and tissue engineering, which allows us to conclude that they meet the safety requirements, beside being bio-adhesive and biodegradable. ${ }^{32,33}$

In light of the foregoing, the objectives of the present in vitro study were to prepare various hydrogel formulations, and then to define the following characteristics of each hydrogel after loading them with insulin: the hydrogel texture; syringeability; and the kinetics of insulin release from the hydrogel into phosphate-buffered saline (PBS) over time.

\section{Material and methods}

This research was conducted at the Faculty of Dentistry of Tishreen University in Lattakia, Syria, and the Faculty of Technical Engineering of the University of Tartous, Syria, between June and November 2019.

\section{Material and equipment}

Chitosan (molecular weight (MW): 100,000-300,000 Da), 87-89\% hydrolyzed PVA (MW: 31,000-50,000 Da) and PEG (average MW: 4,000 Da) were purchased from Acros Organics, Geel, Belgium. Protease-free PVP (MW: 40,000 Da) was purchased from Thermo Fisher Scientific, Waltham, USA. Polyethylene glycol (MW: 10,000 Da) was obtained from Alfa Aesar/Thermo Fisher (Kandel) GmbH, Kandel, Germany. The regular human insulin solution (100 IU/mL) was from ASIA Pharmaceutical Industries, Aleppo, Syria. All other chemicals used were of analytical grade and were purchased from Loba Chemie Pvt Ltd., Mumbai, India.

The equipment we used included the V-630 UV-Vis spectrophotometer (JASCO Corporation, Tokyo, Japan), the LMS-2003D digital hotplate \& stirrer (LabTech SRL, Sorisole, Italy); the ED224S analytical laboratory balance (Sartorius Lab Instruments GmbH \& Co. KG, Goettingen, Germany), the PURELAB ${ }^{\circledR}$ Option-Q DV25 water treatment system (ELGA LabWater, High Wycombe, UK), the Myr V1-R rotational viscometer (Viscotech Hispania SL, El Vendrell, Spain), the TopPette ${ }^{\circledR}$ single-channel pipettor, volume: 10-100 $\mu \mathrm{L}$ (Dragon Laboratory Instruments Ltd., Beijing, China), a pH meter, beakers, glass stirring rods, disposable syringes, and plastic specimen bottles. 


\section{Preparation of hydrogels}

The chemicals underwent no further purification before usage. The chitosan hydrogel was prepared by scattering the precursor into distilled water during magnetic stirring; then drops of acetic acid were gradually added until chitosan completely dissolved. All the other hydrogels were blends of at least 2 polymers. Table 1 shows the components of each formulation as weight percentage (wt\%). The blends were prepared by dissolving the polymers gradually one by one during magnetic stirring in heated water $\left(60-90^{\circ} \mathrm{C}\right)$, which was left for half an hour after that to initiate copolymerization.

Table 1. Composition of the hydrogel formulations (approximate wt\%)

\begin{tabular}{|lc|c|c|c|c|c|}
\hline Formulation & Water & Chitosan & PEG & PVP & PVA & $\mathrm{CaCl}_{2} .2 \mathrm{H}_{2} \mathrm{O}$ \\
\hline F1 & 92.6 & 7.4 & - & - & - & - \\
F2 & 78.1 & - & $10.9^{*}$ & 7.8 & 3.2 & - \\
F3 & 71.4 & - & - & 14.3 & 14.3 & - \\
F4 & 72.0 & - & - & 13.9 & 13.9 & $0.15^{* *}$ \\
F5 & 66.8 & - & - & 26.5 & 6.6 & up to $^{*} 0.05^{* *}$ \\
\hline
\end{tabular}

PEG - polyethylene glycol; PVP - polyvinyl pyrrolidone; PVA - polyvinyl alcohol; * 7.8 wt\% of PEG (MW: 4,000 Da) + 3.1 wt\% of PEG (MW: 10,000 Da);

** weight percentage of pure $\mathrm{CaCl}_{2} \cdot 2 \mathrm{H}_{2} \mathrm{O} ;$; blends with different weight percentages $(0.006 \mathrm{wt} \%, 0.018 \mathrm{wt} \%, 0.03 \mathrm{wt} \%$, and $0.05 \mathrm{wt} \%)$ were prepared.

\section{Loading insulin into the hydrogels}

After preparation, every hydrogel mixture was stored in a refrigerator (at a temperature of $2-8^{\circ} \mathrm{C}$ ) for a minimum of $24 \mathrm{~h}$ to let it relax and to get rid of air bubbles. Then, insulin loading was done by adding a specific volume of the regular human insulin solution $(100 \mathrm{IU} / \mathrm{mL})$ to the hydrogel during magnetic stirring at $\sim 250 \mathrm{rpm}$ for $30 \mathrm{~min}$. Hydrogel samples loaded with various insulin concentrations were prepared. Table 2 presents the concentrations of insulin in the samples of each formulation.

Table 2. Insulin concentrations in the samples of each hydrogel formulation

\begin{tabular}{|l|cccc|}
\hline Formulation & \multicolumn{4}{c}{ Insulin concentration [IU/g] } \\
\hline F1 & 2 & 3 & 4 & 5 \\
F2 & & formulation excluded & \\
F3 & - & 3 & - & - \\
F4 & - & 3 & - & - \\
F5 & 2 & 3 & 4 & 5 \\
\hline
\end{tabular}

\section{Syringeability test}

A sufficient amount of each formulation was pulled into a 5-milliliter disposable syringe. After that, a 20-gauge needle was installed. Finally, the plunger was pressed to release the hydrogel. A formulation was considered syringeable if it passed through the needle upon moderate pressure on the plunger.

\section{Insulin release kinetics}

We prepared PBS following the 2006 Cold Spring Harbor protocol. ${ }^{34}$ Briefly, $8 \mathrm{~g}$ of $\mathrm{NaCl}, 0.2 \mathrm{~g}$ of $\mathrm{KCl}$, $1.8 \mathrm{~g}$ of $\mathrm{Na}_{2} \mathrm{HPO}_{4}$, and $0.24 \mathrm{~g}$ of $\mathrm{KH}_{2} \mathrm{PO}_{4}$ were dissolved in $800 \mathrm{~mL}$ of distilled water. The $\mathrm{pH}$ was adjusted to $\sim 7.4$ (at a temperature of $\sim 25^{\circ} \mathrm{C}$ ) using the potassium hydroxide $(\mathrm{KOH})$ solution. Finally, distilled water was added to reach a total volume of $1 \mathrm{~L}$.

The ultraviolet (UV)-absorbance method for determining and quantifying proteins is based on the absorbance of light at a wavelength of $\sim 280 \mathrm{~nm}$ by the aromatic amino acids tryptophan and tyrosine, and by cysteine/disulfide-bonded cysteine residues in protein solutions. ${ }^{35}$ Hence, simple spectrophotometry without reagents can be used for the quantification of insulin in pharmaceutical preparations. ${ }^{36,37}$ In our study, the wavelength corresponding to the maximum light absorbance by the insulin solute in PBS was determined from the UV-visible spectrum (the maximum absorbance was at $270 \mathrm{~nm}$ ). After that, a calibration curve was drawn depending on the UV absorbed by gradually increasing insulin concentrations $(0.5-4 \mathrm{IU} / \mathrm{mL})$, measured at $270 \mathrm{~nm}$. The concentrations of insulin in the samples were calculated by comparing their absorbance at $270 \mathrm{~nm}\left(\mathrm{~A}_{270}\right)$ with the calibration curve.

In order to characterize the cumulative release of the formulations, $4 \mathrm{~g}$ of each insulin-loaded formulation (the samples) and $4 \mathrm{~g}$ of the same formulation without insulin (the controls) were incubated separately in $15 \mathrm{~mL}$ of PBS in plastic bottles and stored in a refrigerator (at a temperature of $2-8^{\circ} \mathrm{C}$ ). As the first step, the measurements of insulin release were taken at an average temperature of $5^{\circ} \mathrm{C}$ (the unified incubation condition) to compare the performance of different formulations. That was because storing regular insulin at $37^{\circ} \mathrm{C}$, even for less than 1 month, can affect its stability. ${ }^{38}$ Later, the samples of the formulation which showed the longest sustained-release interval (F5 loaded with $2 \mathrm{IU} / \mathrm{g}$ of insulin) were incubated at $37 \pm 0.5^{\circ} \mathrm{C}$ and subjected to insulin release measurements. The release profiles for formulation F5 at the 2 incubation temperatures were compared schematically.

The measurements were performed as follows: after 1 day of incubation, $3 \mathrm{~mL}$ of both the control and the sample were withdrawn after rotating the bottles gently to measure $A_{270}$, and then the withdrawn amounts were returned. The procedure was repeated for each sample at a specified time every day until no more cumulative release was detectable. To calculate the UV absorbance of insulin $\left(\mathrm{IA}_{270}\right)$, the control $A_{270}$ was subtracted from the sample $A_{270}$. The concentration of the released insulin in the sample (RIC) was calculated using equation (1) below, extracted from the calibration curve by applying the Beer-Lambert law:

$$
\mathrm{RIC}=\left(\mathrm{IA}_{270}-0.1\right) / 0.4086[\mathrm{IU} / \mathrm{mL}]
$$

where:

RIC - released insulin concentration [IU/mL];

$\mathrm{IA}_{270}$ - UV absorbance of insulin. 
Assuming that the concentration of insulin in the sample after the loaded insulin had been completely released was FC (FC = insulin load / total sample volume [IU/mL]), then the insulin cumulative release (ICR) from the date of incubation until the date of measurement would be calculated from equation (2):

$$
\mathrm{ICR}=(\mathrm{RIC} / \mathrm{FC}) \times 100[\%]
$$

where:

ICR - insulin cumulative release [\%].

\section{Results}

\section{Texture of the hydrogels}

Formulations F1, F3, F4, and F5 were honeycomb-like, thick liquids with a one-phasic, deposit-free, yellowish, translucent appearance (Fig. 1). Formulation F2 was a bi-phasic, thick liquid and had the bottom layer more viscous than the upper one. Therefore, it was considered heterogeneous and excluded from further characterization. As F5 demonstrated the most favorable insulin release profile, it was submitted to viscosity tests at $5 \pm 1^{\circ} \mathrm{C}$ and $37 \pm 1^{\circ} \mathrm{C}$. The results were $1,630 \pm 40 \mathrm{mPa}$.s and 1,180 $\pm 30 \mathrm{mPa}$.s, respectively.

\section{Syringeability}

All the formulations passed through a 20-gauge needle upon moderate pressure on the plunger, so they were regarded as syringeable.

\section{Insulin release kinetics}

\section{Calibration curve for the insulin solute in phosphate-buffered saline}

For the absorbance values measured using a range of insulin concentrations between 0.5 and $4 \mathrm{IU} / \mathrm{mL}$, the relation between the concentration and $\mathrm{IA}_{270}$ was linear (Fig. 2).

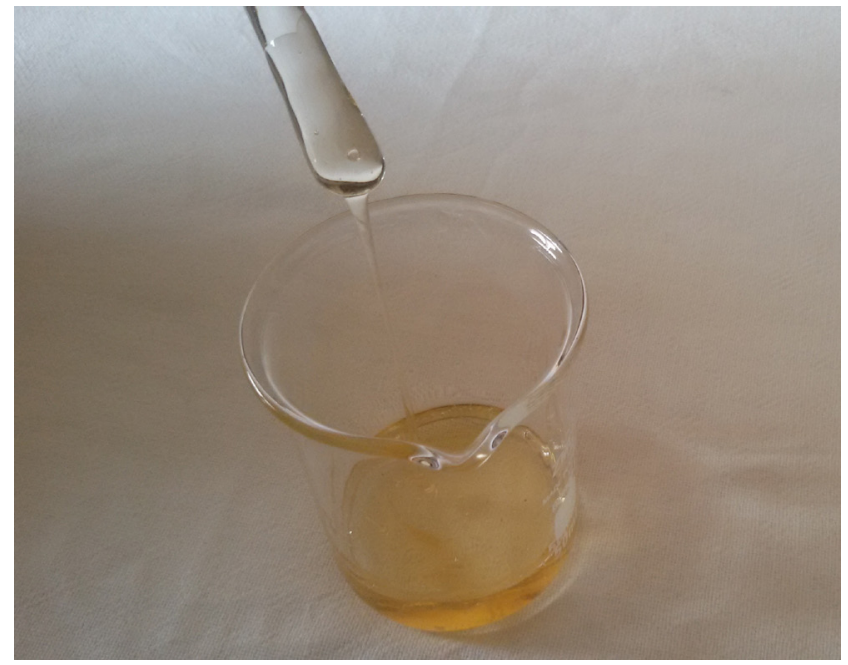

Fig. 1. Appearance of hydrogels F1, F3, F4, and F5

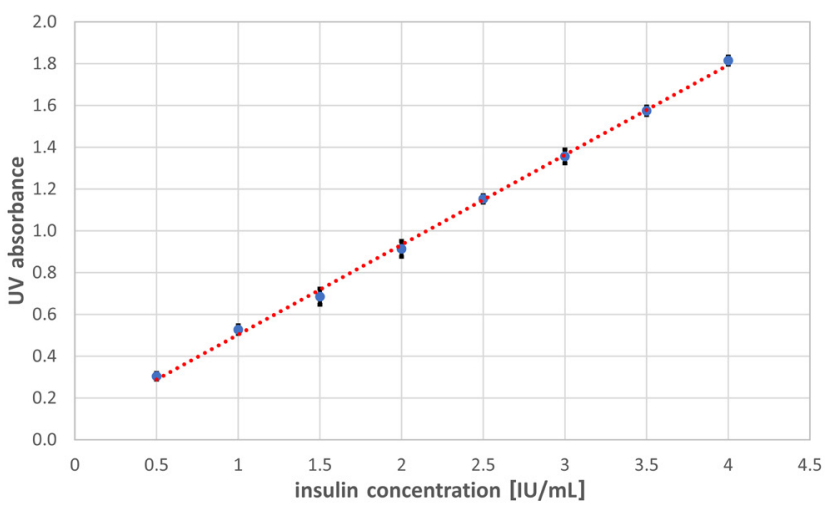

Fig. 2. Calibration curve for the insulin solute in phosphate-buffered saline (PBS) $(n=3)$

The UV-absorbance data is presented as mean $(M) \pm$ standard deviation (SD).

\section{In vitro release of insulin}

The cumulative release of insulin over time for different formulations is shown in Table 3. Generally, for the F1 samples, the greater the insulin load, the faster the ICR was.

Table 3. Cumulative release of insulin over time for different hydrogel formulations

\begin{tabular}{|c|c|c|c|c|c|c|c|c|}
\hline \multirow{3}{*}{ Formulation } & \multirow{3}{*}{$\begin{array}{l}\text { Insulin load } \\
\text { [IU/g] }\end{array}$} & \multicolumn{7}{|c|}{ Time [days] } \\
\hline & & 1 & 2 & 4 & 6 & 8 & 10 & 12 \\
\hline & & \multicolumn{7}{|c|}{ ICR [\%] } \\
\hline \multirow{4}{*}{ F1 } & 2 & $44.00 \pm 3.8$ & $95.15 \pm 2.3$ & 100 & - & - & - & - \\
\hline & 3 & $72.86 \pm 2.9$ & $90.44 \pm 2.6$ & 100 & - & - & - & - \\
\hline & 4 & $98.34 \pm 2.8$ & 100 & - & - & - & - & - \\
\hline & 5 & $81.65 \pm 3.1$ & 100 & - & - & - & - & - \\
\hline $\mathrm{F} 2$ & \multicolumn{8}{|c|}{ formulation excluded } \\
\hline F3 & 3 & 100 & - & - & - & - & - & - \\
\hline $\mathrm{F} 4$ & 3 & $18.70 \pm 2.1$ & & & $89.30 \pm 4.8$ & 100 & - & - \\
\hline \multirow{4}{*}{ F5 } & 2 & UD & $11.43 \pm 1.8$ & - & $44.5 \pm 2.3$ & - & - & $92.42 \pm 3.6$ \\
\hline & 3 & UD & $13.47 \pm 2.2$ & \multicolumn{2}{|c|}{$36.87 \pm 5.1$} & - & $80.00 \pm 2.4$ & $99.42 \pm 1.0$ \\
\hline & 4 & UD & $20.13 \pm 5.0$ & \multicolumn{2}{|c|}{$60.26 \pm 3.0$} & \multicolumn{2}{|c|}{$71.30 \pm 3.1$} & $98.60 \pm 1.2$ \\
\hline & 5 & UD & $26.60 \pm 2.3$ & \multicolumn{2}{|c|}{$64.35 \pm 4.6$} & \multicolumn{2}{|c|}{$78.23 \pm 4.1$} & $99.27 \pm 0.8$ \\
\hline
\end{tabular}

ICR - insulin cumulative release; UD - undetectable. The ICR data is presented as $M \pm S D$. 
The longest release time (in the $3 \mathrm{IU} / \mathrm{g}$ sample) was less than 4 days (Fig. 3). Formulation F3 exhibited the complete release of the loaded insulin within 1 day, while F4 had a regular release profile up to 6 days (Fig. 4). The F5 samples with diverse insulin loads and $0.03 \mathrm{wt} \%$ of calcium chloride dihydrate $\left(\mathrm{CaCl}_{2} \cdot 2 \mathrm{H}_{2} \mathrm{O}\right)$ released insulin faster when the insulin load was bigger. The longest release time (13 days) was for $2 \mathrm{IU} / g$ (Fig. 5).

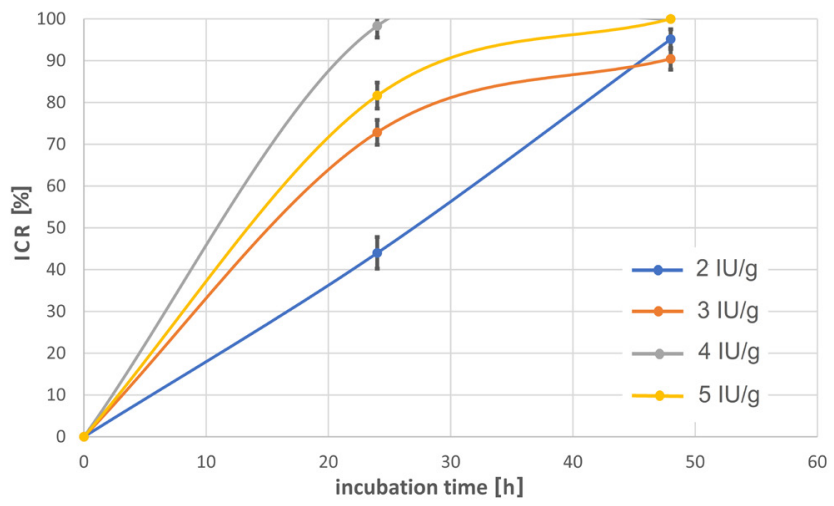

Fig. 3. Cumulative release profiles of insulin for the F1 samples with different insulin loads $(n=3)$

The ICR data is presented as $M \pm S D$.

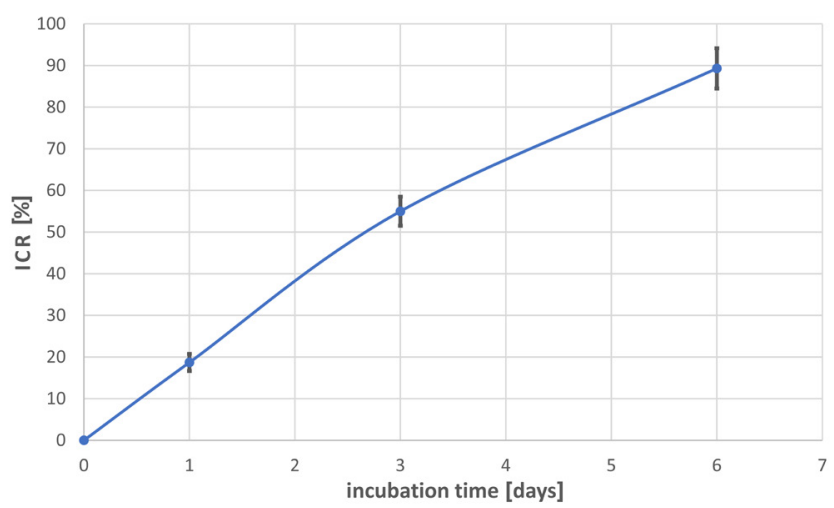

Fig. 4. Cumulative release profile of insulin for the F4 samples loaded with $3 \mathrm{IU} / \mathrm{g}$ of insulin $(n=3)$

The ICR data is presented as $M \pm S D$.

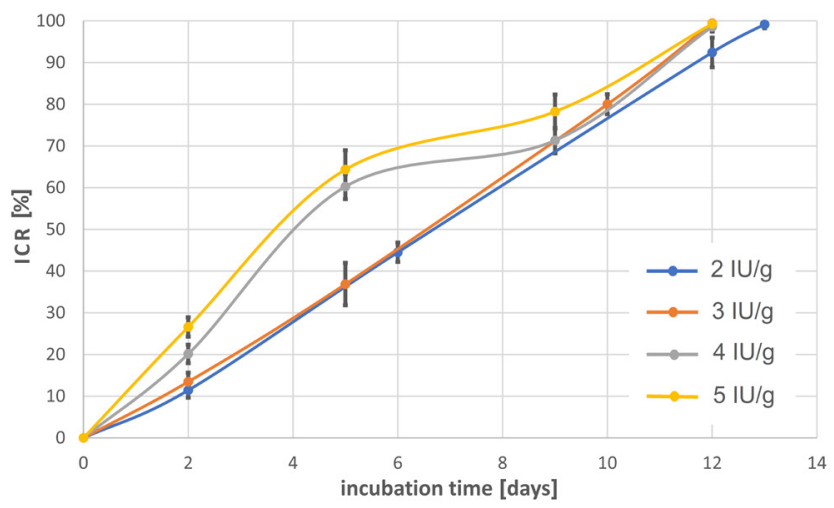

Fig. 5. Cumulative release profiles of insulin for the F5 samples with different insulin loads $(n=3)$

The ICR data is presented as $M \pm S D$.
The weight percentage of $\mathrm{CaCl}_{2} \cdot 2 \mathrm{H}_{2} \mathrm{O}$ in formulation F5 had a significant effect on the insulin release profile. Among the percentages investigated in the present study, $0.03 \mathrm{wt} \%$ gave the longest and most regular release profile (Fig. 6).

Formulation F5 containing 0.03 wt $\%$ of $\mathrm{CaCl}_{2} \cdot 2\left(\mathrm{H}_{2} \mathrm{O}\right)$ and loaded with $2 \mathrm{IU} / \mathrm{g}$ of insulin showed a notable difference in the release kinetics in response to 2 different temperatures of incubation $\left(5^{\circ} \mathrm{C}\right.$ and $\left.37^{\circ} \mathrm{C}\right)$, as illustrated in Fig. 7. At $37^{\circ} \mathrm{C}$, the complete in vitro release of insulin was reached about 4 days faster (9 days compared to 13 days).

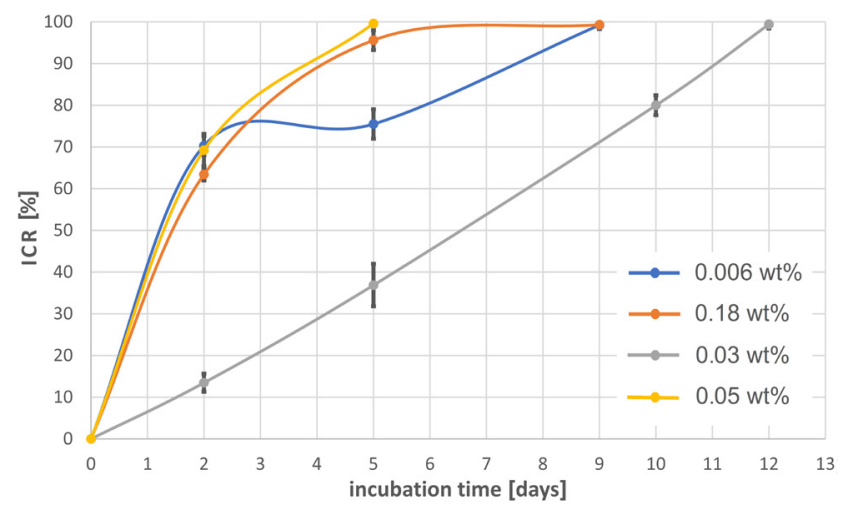

Fig. 6. Cumulative release profiles of insulin for the $\mathrm{F} 5$ samples with different $\mathrm{CaCl}_{2} \cdot 2 \mathrm{H}_{2} \mathrm{O}$ contents, loaded with $3 \mathrm{IU} / \mathrm{g}$ of insulin $(n=3)$ The ICR data is presented as $M \pm S D$.

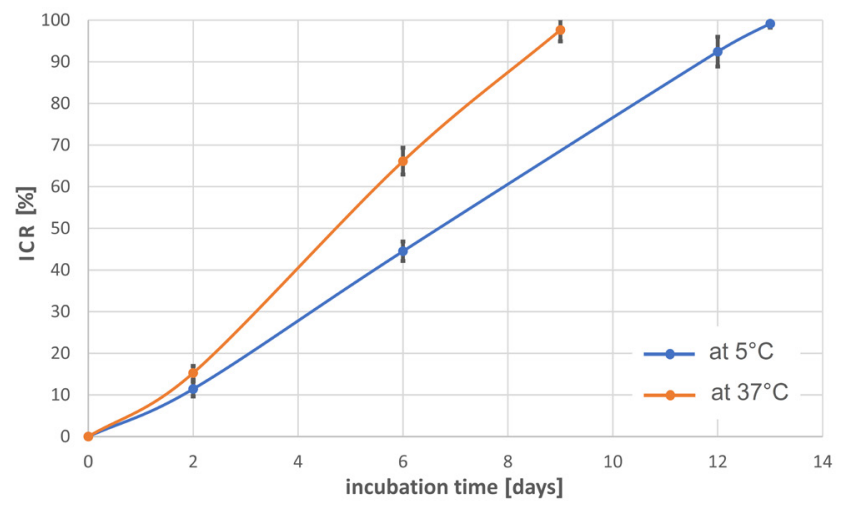

Fig. 7. Cumulative release profiles of insulin for the $\mathrm{F} 5$ samples (0.03 wt $\% \mathrm{CaCl}_{2} .2 \mathrm{H}_{2} \mathrm{O}, 2 \mathrm{IU} / \mathrm{g}$ of insulin) at 2 different temperatures of incubation $\left(5^{\circ} \mathrm{C}\right.$ and $\left.37^{\circ} \mathrm{C}\right)(n=3)$

The ICR data is presented as $M \pm S D$.

\section{Discussion}

Drug release from a matrix takes place through one or more of the following mechanisms: diffusion, swelling, degradation, and erosion, ${ }^{39,40}$ which are matrix-affected. The kind and load of the drug are factors influencing drug release. ${ }^{41}$ No wonder, then, that available LDDSs for periodontal therapy have different drug release kinetics. Clinical studies on Actisite reported concentrations 
of tetracycline $\mathrm{HCl}$ higher than $1,000 \mu \mathrm{g} / \mathrm{mL}$ for a period of 10 days. ${ }^{7}$ PerioChip showed the burst release of about $40 \%$ of the chlorhexidine content in the first $24 \mathrm{~h}$ after application, followed by constant release for 7 days. ${ }^{9}$ Ligosan is claimed to reach 12 days of doxycycline release subgingivally. ${ }^{10}$ The performance of Atridox in terms of chlorhexidine release was similar to PerioChip, as demonstrated by clinical studies with effective antimicrobial concentrations measured in GCF up to 7 days. ${ }^{42}$ The subgingival application of $0.05 \mathrm{~mL}$ of Dentomycin ointment in a clinical trial led to concentrations of minocycline in GCF reaching 1,300 $\mu \mathrm{g} / \mathrm{mL}$ after $1 \mathrm{~h}$, but reduced to $90 \mu \mathrm{g} / \mathrm{mL}$ after $7 \mathrm{~h} .{ }^{43}$ In a trial including 12 patients, Elyzol Dental Gel was applied once into pockets $\geq 5 \mathrm{~mm}$ and metronidazole was detectable in GCF for $36 \mathrm{~h}$, but its concentration was higher than the minimum inhibitory concentration $(1 \mu \mathrm{g} / \mathrm{mL})$ for only $12 \mathrm{~h} .{ }^{44}$ Arestin achieved concentrations of minocycline in GCF $>1 \mu \mathrm{g} / \mathrm{mL}$ up to 14 days. $^{12}$

Local drug delivery systems that have higher crosslinked drug carrier matrices, such as non-absorbable LDDSs, films and chips, seem to achieve relatively longer release intervals. On the other hand, non-absorbable LDDSs need a second appointment for removal. Fibers, films and chips can be tricky to insert into some pockets. Many LDDSs offer initial burst release (e.g., PerioChip). The use of microparticle-based techniques (e.g., Arestin) can overcome these disadvantages, although they entail more complicated procedures, hence higher costs. A few LDDSs have short release intervals (e.g., Dentomycin and Elyzol). The LDDS designed in this study for the local delivery of insulin took good advantage of the abilities of the hydrogel to entrap and release materials, which can be modulated simply by physically blending many polymers and other additives together until the desired release profile is obtained.

Since sufficient viscosity is mandatory for hydrogels to be able to entrap molecules, ${ }^{45}$ in addition to being needed to prevent the hydrogel from leaking from the injection site, we dissolved greater quantities of the precursor as a strategy to increase viscosity during the preparation of the hydrogel. However, the viscosity of the hydrogels was adjusted so that they were injectable. Also, blending many polymers together helped to fine-tune drug release kinetics. Still, the bi-phasic texture of F2 seems consistent with what Inamura et al. indicated about the repulsive interactions and incompatibility of the PEG/PVA and PEG/PVP polymer pairs in water, ${ }^{46}$ which can eventually cause liquid-liquid phase separation in the solution.

The link between increased insulin loads and accelerated release could be explained by more insulin-to-insulin weak bonds forming at the expense of polymer-to-insulin bonds. The effect of the addition of $\mathrm{CaCl}_{2} \cdot 2 \mathrm{H}_{2} \mathrm{O}$ on the insulin release profiles of PVP/PVA blends is similar to its influence posited by Rambabu and Velu on the dye rejection of polyethersulfone ultrafiltration membranes. ${ }^{47}$
This may be ascribed to the steric hindrance initiated by polymer-to-calcium chloride bonds. Steric hindrance restricts the diffusion of the drug from the hydrogel. It also restricts the diffusion of water into the hydrogel, which is responsible for the hydrolysis of drug-to-polymer bonds. Another possible mechanism is that calcium ions form adsorption sites for insulin molecules, making their outdiffusion slower.

\section{Conclusions}

The results of the present study allow the authors to ratiocinate that a linear copolymer-hydrogel composed of PVP, PVA and $\mathrm{CaCl}_{2} \cdot 2 \mathrm{H}_{2} \mathrm{O}$ can provide the sustained release of insulin (in vitro) for a reasonable period. Insulin release intervals can be fine-tuned by changing one or more of the following determinants, which were found to affect the insulin release profile: the hydrogel composition, the insulin load and the $\mathrm{CaCl}_{2} \cdot 2 \mathrm{H}_{2} \mathrm{O}$ content. The design presented may perhaps be beneficial for the local delivery of insulin in patients with periodontitis, as an adjunct to NSPT.

\section{ORCID iDs}

Ali Raeef Abboud (D) https://orcid.org/0000-0002-0790-901X Ali Mohammad Ali (D) https://orcid.org/0000-0002-8906-1904 Tihama Youssef (D) https://orcid.org/0000-0002-6687-4814

\section{References}

1. Lang NP, Lindhe J, eds. Clinical Periodontology and Implant Dentistry. $6^{\text {th }}$ ed. Hoboken, USA: Wiley-Blackwell; 2015:749-761.

2. Krayer JW, Leite RS, Kirkwood KL. Non-surgical chemotherapeutic treatment strategies for the management of periodontal diseases. Dent Clin North Am. 2010;54(1):13-33. doi:10.1016/j.cden.2009.08.010

3. Rajeshwari HR, Dhamecha D, Jagwani S, et al. Local drug delivery systems in the management of periodontitis: A scientific review. J Control Release. 2019;307:393-409. doi:10.1016/j.jconrel.2019.06.038

4. Joshi D, Garg T, Goyal AK, Rath G. Advanced drug delivery approaches against periodontitis. Drug Deliv. 2016;23(2):363-377. doi:10.3109/10717544.2014.935531

5. Thakur VK, Thakur MK, eds. Handbook of Polymers for Pharmaceutical Technologies. Volume 2. Processing and Applications. Austin, USA: Wiley-Scrivener Publishing; 2015:95-113.

6. Javanbakht T, Bérard A, Tavares JR. Polyethylene glycol and poly(vinyl alcohol) hydrogels treated with photo-initiated chemical vapor deposition. Can J Chem. 2016;94(9):744-750. doi:10.1139/cjc-2016-0229

7. Litch JM, Encarnacion M, Chen S, Leonard J, Burkoth TL. Use of the polymeric matrix as internal standard for quantitation of in vivo delivery of tetracycline $\mathrm{HCl}$ from Actisite tetracycline fiber during periodontal treatment. J Periodontal Res. 1996;31(8):540-544. doi:10.1111/j.1600-0765.1996.tb00518.x

8. Kataria S, Chandrashekar KT, Mishra R, Tripathi V, Galav A, Sthapak U. Effect of tetracycline $\mathrm{HCl}$ (Periodontal Plus AB) on Aggregatibacter actinomycetemcomitans levels in chronic periodontitis. Arch Oral Dent Res. 2015;2(1):1-8. doi:10.7243/2053-5775-3-2

9. Paolantonio M, D'Angelo M, Grassi RF, et al. Clinical and microbiologic effects of subgingival controlled-release delivery of chlorhexidine chip in the treatment of periodontitis: A multicenter study. J Periodontol. 2008;79(2):271-282. doi:10.1902/jop.2008.070308

10. Kiesow A, Buchholz M, Sarembe S, Mäder K, Kirchberg M, Eick S. Tetracycline complexes with sustained activity. https://patentscope. wipo.int/search/en/detail.jsf?docld=WO2020089249\&tab=PCTDESC RIPTION. Accessed June 11, 2020. 
11. Lauenstein M, Kaufmann M, Persson GR. Clinical and microbiological results following nonsurgical periodontal therapy with or without local administration of piperacillin/tazobactam. Clin Oral Investig. 2013;17(7):1645-1660. doi:10.1007/s00784-012-0856-4

12. Persson GR, Salvi GE, Heitz-Mayfield LJA, Lang NP. Antimicrobial therapy using a local drug delivery system (Arestin) in the treatment of peri-implantitis. I: Microbiological outcomes. Clin Oral Implants Res. 2006;17(4):386-393. doi:10.1111/j.1600-0501.2006.01269.x

13. Kleine B, Rossmanith WG. Hormones and the Endocrine System. Cham, Switzerland: Springer International Publishing AG; 2016:89-92.

14. Fulzele $\mathrm{K}$, Clemens TL. Novel functions for insulin in bone. Bone. 2012;50(2):452-456. doi:10.1016/j.bone.2011.06.018

15. Fulzele K, Riddle RC, DiGirolamo DJ, et al. Insulin receptor signaling in osteoblasts regulates postnatal bone acquisition and body composition. Cell. 2010;142(2):309-319. doi:10.1016/j.cell.2010.06.002

16. Ferron $M$, Wei J, Yoshizawa $T$, et al. Insulin signaling in osteoblasts integrates bone remodeling and energy metabolism. Cell. 2010;142(2):296-308. doi:10.1016/j.cell.2010.06.003

17. Klein GL. Insulin and bone: Recent developments. World J Diabetes. 2014;5(1):14-16. doi:10.4239/wjd.v5.i1.14

18. Senn JJ, Klover PJ, Nowak IA, Mooney RA. Interleukin-6 induces cellular insulin resistance in hepatocytes. Diabetes. 2002;51(12):3391-3399. doi:10.2337/diabetes.51.12.3391

19. Kurauti MA, Costa-Júnior JM, Ferreira SM, et al. Interleukin-6 increases the expression and activity of insulin-degrading enzyme. Sci Rep. 2017;7:46750. doi:10.1038/srep46750

20. Thrailkill K, Bunn RC, Lumpkin C Jr., et al. Loss of insulin receptor in osteoprogenitor cells impairs structural strength of bone. J Diabetes Res. 2014;2014:703589. doi:10.1155/2014/703589

21. Fai S, Ahem A, Mustapha M, Mohd Noh UK, Bastion MLC. Randomized controlled trial of topical insulin for healing corneal epithelial defects induced during vitreoretinal surgery in diabetics. Asia Pac J Ophthalmol (Phila). 2017;6(5):418-424. doi:10.22608/APO.201780

22. Attia EAS, Belal DMI, El Samahy MH, El Hamamsy MH. A pilot trial using topical regular crystalline insulin vs aqueous zinc solution for uncomplicated cutaneous wound healing: Impact on quality of life. Wound Repair Regen. 2014;22(1):52-57. doi:10.1111/wrr.12122

23. Rezvani O, Shabbak E, Aslani A, Bidar R, Jafari M, Safarnezhad S. A randomized, double-blind, placebo-controlled trial to determine the effects of topical insulin on wound healing. Ostomy Wound Manage. 2009;55(8):22-28. PMID:19717853

24. Zhang XJ, Wu X, Wolf SE, Hawkins HK, Chinkes DL, Wolfe RR. Local insulin-zinc injection accelerates skin donor site wound healing. J Surg Res. 2007;142(1):90-96. doi:10.1016/j.jss.2006.10.034

25. Van Ort SR, Gerber RM. Topical application of insulin in the treatment of decubitus ulcers: A pilot study. Nurs Res. 1976;25(1):9-12. PMID:1107960

26. Wang X, Zhang G, Qi F, et al. Enhanced bone regeneration using an insulin-loaded nano-hydroxyapatite/collagen/PLGA composite scaffold. Int J Nanomedicine. 2018;13:117-127. doi:10.2147/IJN.S150818

27. Paglia DN, Wey A, Breitbart EA, et al. Effects of local insulin delivery on subperiosteal angiogenesis and mineralized tissue formation during fracture healing. J Orthop Res. 2013;31(5):783-791. doi:10.1002/jor.22288

28. Han Y, Zhang XY, Ling EL, Wang DS, Liu HS. Sustained local delivery of insulin for potential improvement of peri-implant bone formation in diabetes. Sci China Life Sci. 2012;55(11):948-957. doi:10.1007/s11427-012-4392-x

29. Bartlett JD, Slusser TG, Turner-Henson A, Singh KP, Atchison JA, Pillion DJ. Toxicity of insulin administered chronically to human eye in vivo. J Ocul Pharmacol. 1994;10(1):101-107. doi:10.1089/jop.1994.10.101

30. Emecen-Huja P, Eubank TD, Shapiro V, Yildiz V, Tatakis DN, Leblebicioglu B. Peri-implant versus periodontal wound healing. J Clin Periodontol. 2013;40(8):816-824. doi:10.1111/jcpe.12127

31. Vedadghavami A, Minooei F, Mohammadi MH, et al. Manufacturing of hydrogel biomaterials with controlled mechanical properties for tissue engineering applications. Acta Biomater. 2017;62:42-63. doi:10.1016/j.actbio.2017.07.028

32. Shi Y, Xiong DS, Peng Y, Wang N. Effects of polymerization degree on recovery behavior of PVA/PVP hydrogels as potential articular cartilage prosthesis after fatigue test. eXPRESS Polym Lett. 2016;10(2):125-138. doi:10.3144/expresspolymlett.2016.13
33. Ozdil D, Wimpenny L, Aydin M, Yang Y. Biocompatibility of biodegradable medical polymers. In: Zhang $X$, ed. Science and Principles of Biodegradable and Bioresorbable Medical Polymers: Materials and Properties. Cambridge, UK: Elsevier (Woodhead Publishing); 2017:379-414.

34. Chazotte B. Labeling Golgi with fluorescent ceramides. Cold Spring Harb Protoc. 2012;2012(8):pdb.prot070599. doi:10.1101/pdb.prot070599

35. Simonian $\mathrm{MH}$. Spectrophotometric determination of protein concentration. Curr Protoc Cell Biol. 2002;15(1):A.3B.1-A.3B.7. doi:10.1002/0471143030.cba03bs15

36. Yilmaz B, Kadioglu Y. Determination of human insulin in pharmaceutical preparation by zero, first and second order derivative spectrophotometric methods. Intl R J Pharmaceut. 2012;2(2):21-29. https://www.yumpu.com/en/document/read/26128170/determinationof-human-insulin-in-scientific-journals. Accessed February 1, 2020.

37. Lassalle VL, Pirillo S, Rueda E, Ferreira ML. An accurate UV/visible method to quantify proteins and enzymes: Impact of aggregation, buffer concentration and the nature of the standard. Curr Top Anal Chem. 2011;8:83-93. http://www.researchtrends.net/tia/article_pdf. asp?in=0\&vn=8\&tid=30\&aid=3333. Accessed February 1, 2020.

38. Vimalavathini R, Gitanjali B. Effect of temperature on the potency \& pharmacological action of insulin. Indian J Med Res. 2009;130(2):166-169. PMID:19797814

39. Muzzarelli RAA. Chitins and chitosans for the repair of wounded skin, nerve, cartilage and bone. Carbohydr Polym. 2009;76(2):167-182. doi:10.1016/j.carbpol.2008.11.002

40. Pillai O, Panchagnula R. Polymers in drug delivery. Curr Opin Chem Biol. 2001;5(4):447-451. doi:10.1016/s1367-5931(00)00227-1

41. Weiser JR, Saltzman WM. Controlled release for local delivery of drugs: Barriers and models. J Control Release. 2014;190:664-673. doi:10.1016/j.jconrel.2014.04.048

42. Garrett S, Johnson L, Drisko CH, et al. Two multi-center studies evaluating locally delivered doxycycline hyclate, placebo control, oral hygiene, and scaling and root planing in the treatment of periodontitis. J Periodontol. 1999;70(5):490-503. doi:10.1902/jop.1999.70.5.490

43. van Steenberghe D, Bercy P, Kohl J, et al. Subgingival minocycline hydrochloride ointment in moderate to severe chronic adult periodontitis: A randomized, double-blind, vehicle-controlled, multicenter study. J Periodontol. 1993;64(7):637-644. doi:10.1902/jop.1993.64.7.637

44. Stoltze K. Concentration of metronidazole in periodontal pockets after application of a metronidazole 25\% dental gel. J Clin Periodontol. 1992;19(9 Pt 2):698-701. doi:10.1111/j.1600-051x.1992.tb02531.x

45. Talukdar MM, Vinckier I, Moldenaers $P$, Kinget R. Rheological characterization of xanthan gum and hydroxypropylmethyl cellulose with respect to controlled-release drug delivery. J Pharm Sci. 1996;85(5):537-540. doi:10.1021/js950476u

46. Inamura I, Akiyama K, Kubo Y. Polymer 2-polymer 3 interactions in water $1 /$ polymer $2 /$ polymer 3 ternary systems. Polym J. 1997;29(2):119-122. doi:10.1295/polymj.29.119

47. Rambabu K, Velu S. Improved performance of $\mathrm{CaCl}_{2}$ incorporated polyethersulfone ultrafiltration membranes. Period Polytech Chem Eng. 2016;60(3):181-191. doi:10.3311/PPch.8482 